\title{
Safety Practice and Professional Exposure to Blood and Blood- Containing Materials in Serbian Health Care Workers
}

\author{
Aleksandra JoviC-VRAnEs ${ }^{1}$, Slavenka JANKoviC ${ }^{2}$ and Boris VRanes ${ }^{3}$ \\ ${ }^{1}$ Institute of Social Medicine, ${ }^{2}$ Institute of Epidemiology, Medical School University of Belgrade and ${ }^{3}$ Institute of \\ Gynaecology and Obstetrics, Clinical Center of Serbia, Serbia and Montenegro
}

\begin{abstract}
Safety Practice and Professional Exposure to Blood and Blood-Containing Materials in Serbian Health Care Workers: Aleksandra JovicVRANES, et al. Institute of Social Medicine, Medical School University of Belgrade, Servia and Montenegro-Safety practice is an important element of workplace safety and quality of health care. To investigate the safety practice and professional exposure to blood and blood-containing materials during a one-year period among Health Care Workers (HCWs) in Serbia. Cross-sectional study of 1559 Serbian HCWs using a self-administered questionnaire. Mantel-Haenszel statistics and multiple logistic regression analysis were used in statistical analysis. Fifty-nine percent (921) of HCWs had skin contact with patients blood, followed by $51 \%$ (791) with needle stick injuries, 38\% (599) with cuts from sharp instruments, and $34 \%$ with contact of eye and other mucosa with patient's blood. Nurses reported professional exposure more often than others. Safety practices consisted of using appropriate barriers (gloves, mask, glasses) in all procedures with patients and were used by $58 \%$, $23 \%$, and $4 \%$ of $\mathrm{HCWs}$, respectively. Doctors protected themselves more regularly than others. Hospital protocols for post exposure prophylaxis and safety disposal of medical waste are not common in Serbian health care settings. Safety practices in use were having hospital guidelines for safety practice in hospitals [odds ratio $(O R)=1.58,95 \%$ confidence interval $(\mathrm{Cl})=1.14-2.19]$, carrying out some form of intervention with risks of infection (OR=3.76, 95\% $\mathrm{Cl}=2.57-5.51$ ), and $\mathrm{HCWs}$ aware of the professional risk of acquiring infection $(\mathrm{OR}=1.48,95 \% \mathrm{Cl}=1.28-$ 1.79). This study indicates that emphasis on work practice, attire, disposal systems and education strategies, should be employed to reduce professional exposure to blood and blood containing materials
\end{abstract}

Received Mar 8, 2006; Accepted Jun 27, 2006

Correspondence to: A. Jovic-Vranes, Institute of Social Medicine, Medical School University of Belgrade, Dr Subotica 15, 11000 Belgrade,Serbia and Montenegro (e-mail: aljvranes@yahoo.co.uk) among HCWs in Serbia.

(J Occup Health 2006; 48: 377-382)

Key words: Safety practice, Professional exposure, Health care workers, Serbia

Health care workers (HCWs) represent a large and growing workforce facing special occupational hazards such as exposures to human blood and body fluids (BBF), placing them at risk to numerous blood borne infections including human immunodeficiency virus (HIV), hepatitis B (HBV), and hepatitis C (HCV) $)^{1,2)}$.

A number of occupational exposures to the blood and body fluids of patients occur each year in health-care settings and blood has been implicated as the source of the exposure in nearly all occupationally acquired infections. Exposures occur through needle sticks or cuts from other sharp instruments contaminated with an infected patient's blood, or through contact of the eye, nose, and mouth with a patient's blood ${ }^{3,4)}$. Today, we know that infectious body fluids include semen, cerebral spinal fluid, amniotic fluid, any inflammatory exudates (pleural, pericardial, peritoneal, synovial), and any body fluid visibly contaminated with blood (stool, urine or saliva). Most exposures do not result in infection. Following a specific exposure, the risk of infection may vary with different factors such as: the pathogen involved and the type of exposure, the amount of blood involved in the exposure, and the amount of virus in the blood at the time of exposure ${ }^{5}$.

The incidence of occupational transmission of HIV to HCWs after percutaneous exposure from an infected source patient is relatively low $(0.3 \%)$, compared with hepatitis $\mathrm{C}(3.0 \%)$, and hepatitis $\mathrm{B}(30.0 \%)^{6}$.

In low-income countries, unsafe practice is comparatively common, placing both patients and HCWs at risk of infections. The risk of occupational infection in such countries is exacerbated by a range of factors including the following: hospital overcrowding, lower ratio of HCWs 
to patients, limited awareness of the risks associated with exposure to blood, failure to implement standard precautions, inadequate supplies of basic safety equipment (including sharp containers and disposable needles) and the need to handle contaminated needles and other sharp instruments that are processed for reuse ${ }^{7,8)}$.

Developed countries recognized the importance of safety practice among HCWs. Protocols of safety practice, safe use and disposal of sharp instruments, and post exposure prophylaxis have been written and used. The Center for Disease Control and Prevention (CDC) designed standard precautions to reduce the risk of transmission of microorganisms from both recognized and unrecognized sources of infection in hospitals. These safety measures include handwashing, gloves, mask, eye protection, face shield, gown, patient care equipment, environmental control, linen, occupational health and bloodborne pathogens, and patient placement ${ }^{9)}$. There are also a large number of studies addressing the professional risk, knowledge, attitude and practice among $\mathrm{HCWs}^{8,10,11)}$. Such studies are rare in Eastern European countries $^{12)}$.

The aim of this study was to examine the use of safety practice, and the incidence of occupational exposure to blood and blood containing materials among HCWs in Serbia during medical procedures.

\section{Methods}

The study was part of the project "Controlling HIV/ AIDS in Serbia: A comprehensive Country Strategy and Emergency Action Plan", and was conducted among 1,559 Serbian HCWs. Data collection was carried out in October 2003.

A total of 1,600 HCWs were included in this study, which represents $2 \%$ of the total number of health care workers in Serbia. The total number of health care workers in Serbia according to the data from the National Institute for Health was 79,905 in 2002 (19,898 doctors, 3,476 dentists, 56,531 nurses, laboratory technicians and other medical staff). The sample was classified according to occupation (doctors, dentists, nurses, laboratory technicians and others). HCWs were from four Clinical Medical Centers (Belgrade, Novi Sad, Nis and Kragujevac), five Primary Health Care Centers and four Dental clinics. HCWs from different departments were analyzed: general practice, gynecology and obstetrics, laboratory, infectious diseases, pneumophtisiology, gastroenterology, hematology, nephrology, urology, alergology and immunology, otorhinolaryngology, surgery (general, orthopedic and traumatology, vascular, maxillofacial), emergency medicine, dermatology, forensic medicine and dentistry.

The data were collected by anonymous selfadministered questionnaires, containing 36 questions. Questions covered the following categories: demographic characteristics (sex, age, profession, and length of work in present position), daily professional activities and practices. HCWs were asked about their exposure to patients' blood and blood containing materials in the period from October 2002 to September 2003 (needle sticks, cuts from sharp instruments, skin contact, and contact of eye and other mucosa), and about safety practice. The survey also inquired about the reactions (post-exposure attitude) to the incident. The use of safety practice was classified into three categories: (i) used in every procedure, (ii) used in some procedures, (iii) not used in any procedure.

A multidisciplinary team consisting of epidemiologists, other public health practitioners, and HCWs developed the questionnaire, which was pre-tested among $96 \mathrm{HCWs}$.

The differences in exposure to human blood and body fluids (needle sticks, cuts from sharp instruments, skin contact and contact of eye and other mucosa), and use of the safety practice (gloves, mask and protection glasses) among HCWs, were compared by the Mantel-Haenszel chi-square test with stratification by five age groups (1930, 31-40, 41-50, 51-60, and over 60). The MantelHaenszel method was also used to calculate the pooled odds ratio (OR) and 95\% confidence intervals (CIs).

A multiple logistic regression was performed in order to calculate the independent odds ratio (OR) of the safety practice use and the corresponding $95 \%$ confidence intervals (CIs). The probability, $\mathrm{p}<0.05$, was taken as the minimum level of significance.

Data were analyzed with SPSS version 12.0.

\section{Results}

Of the 1,600 HCWs, 1,559 completed the questionnaire giving a response rate of $97 \%$. Most of them (80\%) were females. A total of $1,003(64.3 \%)$ were nurses, 402 (25.8\%) doctors, 65 (4.2\%) dentists, 67 (4.3\%) laboratory technicians, and $22(2.0 \%)$ other HCWs (Table 1). The mean age of the respondents was $39.3 \pm 9.4 \mathrm{yr}$. Duration of employment in the current job was $12.2 \pm 9.2 \mathrm{yr}$. Thirty per cent of HCWs were practicing in surgery, and $90.4 \%$ carried out some form of intervention with a risk of infection (contact with blood or other body fluids).

Within the last year $59.1 \%$ of HCWs had skin contact with patient's blood, followed by needle stick injuries in $50.7 \%$, cuts from sharp instruments in $38.4 \%$, and contact of eye and other mucosa with patient's blood in $34.4 \%$ (Table 2).

After adjustment for age we found that, according to the occupational status, exposures (needle sticks, cuts from sharp instruments (sharps) and skin contact with blood or other blood containing materials) had occurred most frequently in nurses and less frequently in doctors. Dentists were exposed significantly higher than other professions only when contact of eye and other mucosa with patient blood and other blood containing materials 
Table 1. Sociodemographic characteristics of health care workers $(\mathrm{N}=1559)$

\begin{tabular}{|c|c|c|c|c|c|c|c|c|c|c|c|c|}
\hline \multirow{2}{*}{$\begin{array}{l}\text { Age group } \\
19-30 \mathrm{yr}\end{array}$} & \multirow{2}{*}{$\begin{array}{l}\text { Gender } \\
\text { Male }\end{array}$} & \multicolumn{2}{|c|}{$\begin{array}{l}\text { Doctors } \\
\mathrm{n}(\%)\end{array}$} & \multicolumn{2}{|c|}{$\begin{array}{c}\text { Dentist } \\
\mathrm{n}(\%)\end{array}$} & \multicolumn{2}{|c|}{$\begin{array}{c}\text { Nurses } \\
\mathrm{n}(\%)\end{array}$} & \multicolumn{2}{|c|}{$\begin{array}{c}\text { Laboratory technicians } \\
\text { n }(\%)\end{array}$} & $\begin{array}{l}\text { Others } \\
\mathrm{n}(\%)\end{array}$ & \multicolumn{2}{|c|}{$\begin{array}{r}\text { Total } \\
\mathrm{n}(\%)\end{array}$} \\
\hline & & 17 & (5.5) & 11 & (3.6) & 16 & $(5.2)$ & 3 & (1.0) & $1 \quad(0.3)$ & 48 & (15.6) \\
\hline & Female & 14 & (4.6) & 5 & (1.6) & 225 & (73.3) & 13 & (4.2) & $2(0.7)$ & 259 & (84.4) \\
\hline \multirow[t]{2}{*}{$31-40 \mathrm{yr}$} & Male & 84 & (16.1) & 12 & (2.3) & 18 & $(3.5)$ & 2 & $(0.4)$ & $2 \quad(0.4)$ & 118 & (22.6) \\
\hline & Female & 86 & (16.5) & 10 & (1.9) & 282 & $(54.1)$ & 21 & (4.0) & $4 \quad(0.8)$ & 403 & (77.4) \\
\hline \multirow[t]{2}{*}{$41-50 \mathrm{yr}$} & Male & 80 & $(15.0)$ & 8 & (1.5) & 16 & (3.0) & 1 & $(0.2)$ & $4 \quad(0.8)$ & 109 & (20.5) \\
\hline & Female & 76 & (14.3) & 8 & (1.5) & 320 & $(60.0)$ & 15 & (2.8) & $5 \quad(0.9)$ & 424 & (79.5) \\
\hline \multirow[t]{2}{*}{$51-60 \mathrm{yr}$} & Male & 20 & (10.6) & 5 & (2.7) & 2 & (1.1) & 1 & $(0.5)$ & $2 \quad(1.1)$ & 30 & (16.0) \\
\hline & Female & 19 & (10.1) & 3 & (1.6) & 123 & $(65.4)$ & 11 & (5.9) & $2 \quad(1.1)$ & 158 & (84.0) \\
\hline \multirow[t]{2}{*}{$60+$} & Male & 4 & $(40.0)$ & 1 & $(10.0)$ & & - & - & & - & 5 & $(50.0)$ \\
\hline & Female & 2 & $(20.0)$ & 2 & $(20.0)$ & 1 & (10.0) & - & - & - & 5 & $(50.0)$ \\
\hline
\end{tabular}

$\%$ indicates the percentage of HCWs from each age group.

Table 2. Exposure to blood and blood containing materials among health care workers

\begin{tabular}{|c|c|c|c|c|c|c|c|c|c|c|c|c|}
\hline & \multicolumn{3}{|c|}{ Needle sticks } & \multicolumn{3}{|c|}{ Cuts from sharps } & \multicolumn{3}{|c|}{ Skin contact } & \multicolumn{3}{|c|}{ Contact of eye and other mucosa } \\
\hline & $\mathrm{N}(\%)$ & OR & $95 \% \mathrm{CI}$ & $\mathrm{N}(\%)$ & OR & $95 \% \mathrm{CI}$ & $\mathrm{N}(\%)$ & OR & $95 \% \mathrm{CI}$ & $\mathrm{N}(\%)$ & OR & $95 \% \mathrm{CI}$ \\
\hline Doctors & $\begin{array}{l}153 \\
(38.1)\end{array}$ & $0.53^{* * *}$ & $0.42-0.67$ & $\begin{array}{l}101 \\
(25.1)\end{array}$ & $0.44^{* * *}$ & $0.34-0.59$ & $\begin{array}{l}202 \\
(50.2)\end{array}$ & $0.65^{* * *}$ & $0.52-0.83$ & $\begin{array}{l}143 \\
(35.5)\end{array}$ & 1.07 & $0.84-1.36$ \\
\hline Dentists & $\begin{array}{l}41 \\
(63.1)\end{array}$ & 1.67 & $1.01-2.85$ & $\begin{array}{c}28 \\
(43.1)\end{array}$ & 1.23 & $0.74-2.04$ & $\begin{array}{l}44 \\
(67.7)\end{array}$ & 1.41 & $0.83-2.42$ & $\begin{array}{c}37 \\
(56.9)\end{array}$ & $2.67^{* * *}$ & $1.62-4.41$ \\
\hline Nurses & $\begin{array}{l}569 \\
(56.7)\end{array}$ & $1.89^{* * *}$ & $1.52-2.34$ & $\begin{array}{l}426 \\
(42.5)\end{array}$ & $1.63^{* * *}$ & $1.31-2.04$ & $\begin{array}{l}632 \\
(63.0)\end{array}$ & $1.51^{* * *}$ & $1.22-1.87$ & $\begin{array}{l}336 \\
(33.5)\end{array}$ & 0.89 & $0.72-1.12$ \\
\hline $\begin{array}{l}\text { Laboratory } \\
\text { technicians }\end{array}$ & $\begin{array}{c}24 \\
(35.8)\end{array}$ & $0.52 *$ & $0.11-3.11$ & $\begin{array}{c}39 \\
(58.2)\end{array}$ & $2.34^{* * *}$ & $1.42-3.85$ & $\begin{array}{c}35 \\
(52.2)\end{array}$ & 0.73 & $0.45-1.19$ & $\begin{array}{l}18 \\
(26.9)\end{array}$ & 0.69 & $0.39-1.19$ \\
\hline Others & $\begin{array}{c}4 \\
(18.2)\end{array}$ & $0.21^{* *}$ & $0.07-0.62$ & $\begin{array}{c}5 \\
(22.7)\end{array}$ & 0.46 & $0.17-1.25$ & $\begin{array}{c}8 \\
(36.4)\end{array}$ & 0.41 & $0.17-0.97$ & $\begin{array}{c}2 \\
(9)\end{array}$ & $0.18^{*}$ & $0.04-0.79$ \\
\hline Total & $\begin{array}{l}791 \\
(50.7)\end{array}$ & & & $\begin{array}{l}599 \\
(38.4)\end{array}$ & & & $\begin{array}{l}921 \\
(59.1)\end{array}$ & & & $\begin{array}{l}536 \\
(34.4)\end{array}$ & & \\
\hline
\end{tabular}

${ }^{*} p<0.05,{ }^{* *} p<0.01,{ }^{* * *} p<0.001$ by the Mantel-Haenszel chi-square test with stratification by age group (19-30, 31-40, 41-50, 51-60, 60+).

$\mathrm{OR}=$ adjusted Mantel-Haenszel odds ratio; $\mathrm{CI}=$ confidence interval.

were considered. Cuts from sharps occurred mainly in laboratory technicians (Table 2).

More than half $(57.6 \%)$ of the HCWs used gloves in every procedure with patients, $22.9 \%$ used masks, and only a few $(3.7 \%)$ used protection glasses.

Doctors protected themselves with gloves, masks and protection glasses more regularly than other practitioners.

The habit of using a mask and protection glasses in all procedures with patients was highest among dentists. Nurses reported lower rates of self protection. We found that no laboratory technicians and other HCWs used mask and protection glasses in any medical procedure. Protection glasses were least commonly used among HCWs-72.9\% never used them (Table 3).

If an exposure had occurred, $968(62.1 \%)$ of respondents had reported the event to epidemiological service, 1,026 (65.8\%) had performed some serological test and 1,195 (76.7\%) had asked about the patient's infection status.

Nearly $80 \%$ of respondents had not been informed about guidelines for safety practice, and the protocols of post exposure prophylaxis, or such protocols did not exist in their work environment.

Only $36 \%$ of HCWs reported use of safety containers for disposal of contaminated medical waste, and half of the respondents $(50.8 \%)$ put it together with other waste.

Using logistic regression analysis we found that safety practice was higher among the HCWs who had hospital guidelines for safety practice $(\mathrm{OR}=1.58,95 \%$; $\mathrm{CI}=1.14$ $2.19)$, those who carried out some form of intervention 
Table 3. Appropriate barriers used by health care workers in all procedures with patients

\begin{tabular}{|c|c|c|c|c|c|c|c|c|c|}
\hline & \multicolumn{3}{|c|}{ Gloves } & \multicolumn{3}{|c|}{ Mask } & \multicolumn{3}{|c|}{ Glasses } \\
\hline & $\mathrm{N}(\%)$ & OR & $95 \% \mathrm{CI}$ & $\mathrm{N}(\%)$ & OR & $95 \% \mathrm{CI}$ & $\mathrm{N}(\%)$ & OR & $95 \% \mathrm{CI}$ \\
\hline Doctors & $\begin{array}{c}262 \\
(65.2)\end{array}$ & $1.58^{* * * *}$ & $1.24-2.01$ & $\begin{array}{c}117 \\
(29.1)\end{array}$ & $1.55^{* *}$ & $1.19-2.02$ & $\begin{array}{c}23 \\
(5.7)\end{array}$ & $1.86^{*}$ & $1.08-3.23$ \\
\hline Dentist & $\begin{array}{c}45 \\
(69.2)\end{array}$ & 1.57 & $0.91-2.71$ & $\begin{array}{c}24 \\
(36.9)\end{array}$ & $1.93^{*}$ & $1.15-3.23$ & $\begin{array}{c}12 \\
(18.5)\end{array}$ & $7.55^{* * *}$ & $3.71-15.36$ \\
\hline Nurses & $\begin{array}{c}544 \\
(54.2)\end{array}$ & $0.67^{* * * *}$ & $0.54-0.83$ & $\begin{array}{c}216 \\
(21.5)\end{array}$ & 0.83 & $0.65-1.06$ & $\begin{array}{c}22 \\
(2.2)\end{array}$ & $0.35^{* * *}$ & $0.19-0.60$ \\
\hline $\begin{array}{l}\text { Laboratory } \\
\text { technicians }\end{array}$ & $\begin{array}{c}36 \\
(53.7)\end{array}$ & 0.83 & $0.51-1.37$ & - & - & - & - & - & - \\
\hline Others & $\begin{array}{c}11 \\
(50.0)\end{array}$ & 0.76 & $0.32-1.79$ & - & - & - & - & - & - \\
\hline Total & $\begin{array}{c}898 \\
(57.6)\end{array}$ & & & $\begin{array}{c}357 \\
(22.9)\end{array}$ & & & $\begin{array}{c}57 \\
(3.7)\end{array}$ & & \\
\hline
\end{tabular}

${ }^{*} p<0.05,{ }^{* *} p<0.01,{ }^{* * *} p<0.001$ by the Mantel-Haenszel chi-square test with stratification by age group (19-30, 31-40, 41-50, 51-60, and more than $60 \mathrm{yr}$ ). OR=adjusted Mantel-Haenszel odds ratio; $\mathrm{CI}=$ confidence interval.

Table 4. Safety practices used by health care workers—multiple logistic regression analysis

\begin{tabular}{|c|c|c|c|c|c|c|}
\hline \multirow{2}{*}{ Variable } & \multicolumn{4}{|c|}{ Safety practice use } & \multirow[t]{2}{*}{ OR } & \multirow[t]{2}{*}{$95 \% \mathrm{CI}$} \\
\hline & & No & & Yes & & \\
\hline & 471 & $(30.2 \%)$ & 1,088 & $(69.8 \%)$ & & \\
\hline Existing protocols of post exposition prophylaxis & 33 & $(17.6 \%)$ & 155 & $(82.4 \%)$ & $1.57^{*}$ & $1.00-2.45$ \\
\hline Existing hospital guidelines for safety practice & 71 & $(20.7 \%)$ & 272 & $(79.3 \%)$ & $1.58^{* *}$ & $1.14-2.19$ \\
\hline $\begin{array}{l}\text { Intervention with a risk of infection (contact } \\
\text { with blood and other body fluids) }\end{array}$ & 397 & $(28.2 \%)$ & 1,013 & $(71.8 \%)$ & $3.76^{* * *}$ & $2.57-5.51$ \\
\hline Aware of the professional risk of acquiring infection & 450 & $(31.1 \%)$ & 996 & $(68.9 \%)$ & $1.48^{* *}$ & $1.28-1.79$ \\
\hline
\end{tabular}

Total of $1559 \mathrm{HCWs}$; OR=odds ratio; $\mathrm{CI}=$ confidence interval, ${ }^{*} p<0.05,{ }^{*} p<0.01,{ }^{*} * *<<0.001$.

with a risk of infection, e.g. contact with blood or other body fluids $(\mathrm{OR}=3.76,95 \% \mathrm{CI}=2.57-5.51)$, and among HCWs who were aware of the professional risk of acquiring infection $(\mathrm{OR}=1.48,95 \% \mathrm{CI}=1.28-1.79)$. Safety practice use among HCWs who had protocols for post exposure prophylaxis in their hospitals was on the border of the significance (Table 4).

\section{Discussion}

HCWs are a very important group in the prevention and management of blood-borne infections. Both anecdotal and survey data suggest that health-care students and professional health care staff receive variable and often inadequate education and training in infection control. Avoiding contact with potentially infected blood, body fluids and tissues is an essential component of risk reduction for HCWs. Preventing needle stick injuries and other potential exposures is likely to have a significant impact on reducing infection in most health-care settings ${ }^{13)}$.

We evaluated safety practice among HCWs in Serbia and exposure to blood and blood-containing materials.

No nationally accepted standardized method for collecting and calculating sharp injuries has been developed. However, the Exposure Prevention Information Network is widely used in the USA, Canada, Italy and Japan. In the USA, it was estimated that 600,000-800,000 injuries from sharps occur per year, whereas in the UK, 100,000 injuries from sharps were estimated to occur among all $\mathrm{HCWs}^{6}$. There are no data about such injuries in Serbia.

Data from the literature suggest that needle stick injuries and cuts are the most commonly reported routes of blood and body fluids exposure among $\mathrm{HCWs}^{7}$. In our study, the most common accidental injury was a skin contact with patient blood $(59.1 \%)$, followed by needle 
sticks $(50.7 \%)$ and cuts by sharp instruments $(38.4 \%)$. Nurses were more exposed to needle sticks and laboratory technicians to cuts by sharps. These exposure rates for different occupation groups are parallel to the rates of invasive procedures they carry out despite the educational differences. Doctors generally fail to report sharps and needle stick injuries, and a number of studies have confirmed this. Nurses appear to have higher reporting rates and more frequent exposure ${ }^{14-16)}$. The proportion of HCWs reporting professional exposure in this study is lower than that in some other low-income countries ${ }^{12)}$. More than three quarters of Chinese and Indian nurses and $69 \%$ of South African interns experienced percutaneous injuries in the preceding year ${ }^{7,17-19)}$. However, a comparison of proportions and numbers of exposures reported in different studies should be viewed with caution because there is considerable variability in a range of critical factors, including the method of data collection, sample size, type of HCWs surveyed, and extent of involvement in risk procedures.

HCWs do not use adequate protection (such as gloves, protection glasses or a mask), in all medical procedures with patients. This could be explained by the fact that nearly $80 \%$ of the respondents had not been informed about different guidelines for safety measures and protocols of post exposure prophylaxis or such protocols did not exist at their workplaces. HCWs encountered problems with comprehension, acceptability and applicability of protocols. Protocols are not tailored to the practical needs of different professional groups, probably because $\mathrm{HCW}$ s have rarely been involved in writing them and they are governed more by legal considerations than applicability.

Among the HCWs we studied, 57.6\% wore gloves for all procedures and 3\% did not wear gloves for any procedure. Wearing gloves for all procedures was most frequently reported by doctors and dentists. Some studies suggest that 8-33\% of HCWs routinely use gloves during all procedures in which they are exposed to blood ${ }^{20-22)}$.

When interpreting the findings of this study, a number of limitations should be considered. Retrospective reporting of occupational exposures is subject to recall bias. Respondents were asked about the number of incidents which had occurred in the last year. Moreover, the cross-sectional study design did not allow us to establish causal relationships among variables. We must not forget that these data provide a window into professional exposure and practice among HCWs during a period of dramatical political changes in Serbia.

An important strength of this study was the very high response rate. Our results may stimulate further research, and provide a valuable reference point for future studies of this issue.

We can say that the present data provide important messages on education and training of HCWs. Training on risk management and individual responsibilities regarding safety, participation of HCWs in protocol development, and the support of management to avoid reversion to previous habitual behavior can improve the present situation of infection control. Employers should provide written protocols for prompt reporting, evaluation, counseling, treatment, and follow-up of occupational exposures. This could increase the level of protection of $\mathrm{HCW}$ s and patients, and optimize availability of medical care for all who need it.

Acknowledgment: This work was supported by GFATM (The Global Fund to Fight Aids, Tuberculosis and Malaria: Grant No. SER-102-G01-H-00) and by the Ministry of Science and Ecology of Serbia, contract No 101460, 2002-2005.

\section{References}

1) Dement MJ, Epling C, Ostbye T, Pampeii AL and Hunt LD: Blood and body fluid exposure risk among HCWs: Results from the Duke health and safety surveillance system. Am J Ind Med 46, 637-648 (2004)

2) Center for Disease Control: Updated U.S. Public Health Services guidelines for the management of occupational exposures to HBV, HCV, and HIV and recommendations for postexposure prophylaxis. Morbidity Mortality Weekly Report (MMWR) 50, 142 (2001)

3) Center for Disease Control and Prevention. Exposure to Blood. What Health care Personnel Need to Know. Atlanta: CDC, 2003.

4) Wnuk MA: Occupational exposure to HIV in health care workers. Med Sci Monit 9, 249-252 (2003)

5) Fokin AA, Robicsek F and Masters TN: Accidental injuries by HIV contaminated instruments in health care provider or research environments: Can seroconversion be prevented? Am Surg 66, 14-21 (2000)

6) Trim CJ and Elliott TSJ: A review of sharps injuries and preventative strategies. J Hos Inf 53, 237-242 (2003)

7) Kermode M, Jolley D, langham B, Santhosh M and Crofts N: Occupational exposure to blood and risk of bloodborne virus infection among health care workers in rural north India health care settings. Am J Infect Control 33, 34-41 (2005)

8) Kermode M. Unsafe injections in low-income country health settings: need for injection safety promotion to prevent the spread of blood-borne viruses. Health Prom Int 19, 95-103 (2004)

9) Division of Healthcare Quality Promotion (DHQP). Standard Precautions. (onlin), available from <http:// www.cdc.gov>, (accessed 2005-04-01).

10) Tan L, Hawk C and Sterling ML: Report of the Council on Scientific Affairs. Preventing needle stick injuries in health care settings. Arch Intern Med 161, 929-936 (2001)

11) Munro R: Solving the needle stick nightmare. Nursing Times 97, 12 (2001) 
12) Jovic-Vranes A, Jankovic S, Vukovic D, Vranes B and Miljus D: Risk perception and attitudes towards HIV in Serbian Health Care Workers. Occup Med (Lond) 56, 275-278 (2006)

13) Moloughney BW: Transmission and postexposure management of blood borne virus infections in the health care setting: where are we now? CMAJ 165 , 445-451 (2001)

14) Kumar R, Monah N, Seenu V, Nandi M and Sarma NK: Knowledge, attitude and practices towards HIV among nurses tertiary care teaching hospital: two decades after the discover. J Commun Dis 34, 245$256(2002)$

15) Scoular A, Watt AD, Watson $M$ and Kellz B: Knowledge and attitudes of hospital staff to occupational exposure to blood borne viruses. Commun Dis Public Health 3, 247-249 (2000)

16) Smith DRE, Leggat PA and Takahashi K: Percutaneus exposure incidents among Australian hospital staff. Int J Occup Saf Ergon 11, 323-330 (2005)

17) Logez G, Soyolgerel R, Fields S, Hutin L, Hutin Y. Rapid assessment of injection practice in Mongolia; WHO: Pilot-testing the WHO tools to assess and evaluate injection practice a summary of 10 assessments coordinated by WHO in seven countries (2000-2001). Geneva: WHO, 2003.

18) Phipps W, Honghong W, Min Y, Burgees J, Pellico L, Watkins CW, Gouping $\mathrm{H}$ and Williams A: Risk of medical sharps injures among Chinese nurses. Am J Infect Control 30, 277-282 (2002)

19) Karstaedt AS and Pantanowitz L: Occupational exposure of interns to blood in a area of high HIV seroprevalence. S Afr Med J 91, 57-61 (2001)

20) Shiao J, Guo L and McLaws ML: Estimation of the risk of blood borne pathogens to health care workers after a needle sticks injury in Taiwan. Am J Infect Control 30, 15-20 (2002)

21) Olsen RJ, Lynch p, Coyle MB, Cummings J, Bokete T and Stamm WE: Examination gloves as barriers to hand contamination in clinical practice. J Am Med Assoc 270, 350-353 (1993)

22) Rabaud C, Zanea A, Mur JM, Blech MF, Dazy D, May $\mathrm{T}$ and Guillemin F: Occupational exposure to blood: search for a relation between personality and behavior. Infect Control Hosp Epidemiol 21, 564-574 (2000) 